\title{
EL VALOR ESTETICO DE LOS RELIEVES MAYAS DEL ANTIGUO IMPERIO
}

\author{
POR \\ SALVADOR TOSCANO
}

S I en alguna rama del arte los antiguos mayas alcanzaron formas refina$D$ das y de una acabada belleza, ftué eil el alto y en el bajorrelieve del Antiguo Imperio, siglos IV al IX, en ciudades como Piedras Negras, Yaxchilán Copán, Palenque, Tikal, Uaxactun, etc. Hacia fines del siglo VI y durante los siglos VII y VIII —ronología Goodman-Hernández-Thompson-, en especial los mayas de la cuenca del Usumacinta, han esculpiclo estelas y dinteles que podrian figurar entre las mejores piezas asirias, egipcias y griegas primitivas. :

Pero esta edad de oro, este floreciniento, es el producto de un lento ascenso cultural cuyos origenes apenas empezanos a conocer. I a cerámica. en este caso, es más elocuente que la piedra: sabemos de una etapa arcaica, aparentemente menos antigua que la del Valle de México, en finca Aréralo, cerca de Guatemala (Gamio, 1926), Cerro Zapote, San Salvador, (Lothrop, 1926-1927) ; Uaxactun, Guatemala (Ricketson): Holmul (Merwin y Vaillant); Valle de Uloa, Honduras (Gordon); San José, Honduras Británicas ('Thompson); Atitlán y Zacualpa, Guatemala (Lotlurop). Esta cerámica, en 
que el rasgo hierático, terrible, se ha acentuado, es contemporánea de las esculturas de Miraflores, cerca de Guatemala y de El Salvador-correspondientes en estilo y época a los llamados "danzantes" de Monte Albán-. Sin embargo, este estilo proto-histórico no revela aún los caracteres de lo que habrá de ser el estilo clásico maya. Este se habrá de elaborar lentamente a través de una época de transición, época II, que aparentemente coincide con la llamada cultura olneca. Thompson ha señalado este carácter en el estrato inferior de todas las culturas: mascarones del templo E-VII Sub, Uaxactun, danzantes de Monte Albán, cabeza y mascarón de la estela de Tres Zapotes, asi como la estatuilla de Tuxtla y las hachas de Veracruz.

El estilo de los mayas de los tiempos históricos se realiza a través de estas dos épocas, la arcaica y la proto-histórica de transición, desde una fecha remota y desconocida para nosotros hasta los siglos II al IV de la Era Cristiana, pues debemos concederle un tiempo considerable de elaboración en el cual se cristalizan las formas típicas mayas más usuales, realizando no sólo su cosmogonía y concepciones mitológicas, sino hasta su más común y barroca indumentaria.

Probablemente entonces el relieve se manifestó, más que en el esgrafío de materias pétreas, en el trabajo en madera desaparecido para nosotros y en el modelado en cerámica. Primero se esgrafió el contorno, la siluteta de la figura, hendiendo la materia con sílex y hueso - nótese que los mayas no llegaron a conocer ni el cobre ni el bronce, lo que hace todavía más admirables sus relieves-; más adelante se cuidó de ahuecar las figuras, recortando y modelando la imagen, procediniento que inicialmente se observa en los danzantes de Monte Albán, procurando ya modelar las formas redondas del cuerpo. Más aún, si en un principio las actitudes son rígidas y conservan la horizontalidad de la estatuaria regida por la ley de la frontalidad, pronto habrá composición y movimiento, llegándose a supremas conquistas en Piedras Negras, Guatemala. Además, si inicialmente el relieve sólo trata a la figura humana de perfil, más adelante habrá de esculpirla vista de frente, con excepción del rostro que lo vuelven a un lado y los pies que los sacan hacia afuera; sin embargo, no son extraños los rostros totalmente vistos de frente, asi en Naranjo como en Piedras Negras.

Las esculturas más antiguas de la arqueología maya son todavia un problema para la ciencia americanista." Las primeras fechas frecuentemente han sido tomadas como recordatorias, por lo que no es posible todavía fijar tina cronologia evolutiva de los estilos. Es cierto que la estatuilla del Dios Ave 
de San Andrés 'Tuxtla, Veracruz, ¿objeto de importación?, es considerada por Morley como "posiblemente histórica y posiblemente contemporánea", por lo que en sus rasgos geométricos y rígidos, acentuadamente arcaicos, nos encontramos con el primer monumento proto-maya. Las otras fechas han sido tomadas como recordatorias y aun como falsificaciones: la del vaso de Uaxactun y algunos dinteles y estelas de Naranjo y Yaxchilán, asi como la estela de Eil Baúl, Guatemala (26 D. C.), y es todavia materia de discusión la lectura de la estela 1 de Tres Zapotes, cerca de San Andrés 'Tuxtla, con la clata más antigua de los mayas, 36 años antes de la Era Cristiana. que para su validez abona el decorarla un mascarón de rigidez arcaica, muy semejante por su estilo cubista y fuertemente geométrico a los de la pirámide E-VII Sub de Uaxactun.

Las primeras fechas que tradicionalmente abren los horizontes históricos, son las de la placa de jadeita de Leyden, encontrada en Río Graciosa, Honduras Británicas, con 320 D. C., que por su perfección y por su vestuario altamente barroco, parece indicarnos que se trata de una placa trabajada en la última época, pero inscrita con una fecha recordatoria retrospectiva; la otra fecha, la de la estela 9 de Uaxactun, Guatemala, 327 D. C., parece tratarse realmente del primer monumento histórico de estilo maya, asi por el bloque irregular y la forma grosera de su trabajo, como por su acentuado arcaismo.

Ya para los siglos V y VI se ha iniciado francamente la gran época y los estilos clásicamente mayas, no sólo en Uaxuctun donde se continúa esculpiendo, sino en Tikal, Copán y en algunas ciudades de la cuenca del Usumacinta, llegando este estilo a ciudades tan alejadas como Tulum y Macanxoc, Quintana Roo. Y uno de los últimos monumentos del siglo IX, siglo en el cual cesa toda actividad en el Antiguo Imperio, es la estela 10 de Seibal, inscrita con la fecha 849, esculpida en el barroco más dinámico y más agudamente elaborado.

Infortunadamente para el cabai entendimiento de los relieves mayas, los ejemplares que restan para nosotros han perdido su riqueza policroma. Los mayas, como los griegos, jamás respetaron la belleza del material. Debe recordarse que frecuentemente manejaron el alabastro, algunas clases de mármoles, jadeítas y calizas de grano fino, y, sin embargo, fueron recubiertos por una capa de pintura. Quizá podamos explicar esta tendencia a la viveza cromática atendiendo a la naturaleza meridional de México, a la nitidez de su atmósfera y a los colores tropicales de su flora y te su fauna. Maler nos 
ha descrito los restos de pignentos del colorido de un dintel de Yaxhilán: marco, azul; fondo de la esccna y jeroglificos, de un rojo vivo; personajes, vestuario y ornamento, en colores verde o amarillo. De este arte, pues, conocemos sólo la fisonomía arqutreológica. Esto se hace todavia más sensible cuando, como sucede en Chichén-Itzá, restan ejemplares policromados juntos con algunos que conservan su color, por ejemplo, las columnas y la columnata del Templo de los Guerreros cuyos relieves, poco profundos y faltos de color, no despiertan en nosotros absolutamente ninguna sensación de belleza, en contraste con las columnas que sobreviven de un templo interior, llamado del Chac Mool, bajo los cimientos del Templo_de los Guerreros, que al ser descubiertas recientemente conscrvaban en magnífico estado sus colores, acentitando la belleza y la energia del relieve.

I'or otra parte, debe recordarse que estos relieves de la Gran Epoca nunca tuvieron existencia autónoma en el arte maya. Jamás se les concibió como piezas aisladas, sino como parte ornamental de la arquitectura. No obstante, al contrario de nuestro barroco en donde sólo tienen una función secundaria ya que su belleza depencle de la dinámica del conjunto (por ejemplo la imagen de un retablo o de una fachada), entre los mayas se atendió a su belleza como si hubieren sido concebidos como piezas autónomas.

Los mayas tuvieron un verdadero conocimiento del valor técnico del relieve, ya que supieron aplicar clásicamente el alto y el bajo relieve según se tratare de exteriores o interiores, prefiriéndose el primero en aquellas partes donde la luz del sol los heria contrastándolos fuertemente - motivos geométricos, mascarones, esculturas y aún escenas humanas en las estelas-, prefiriéndose el bajorrelieve para los interiores. En Palenque, por ejemplo, el modelado en estuco, muy próximo al medio relicve, se prefiere en los muros rle los templos; y los bajorrelieves de los tableros, verdaderamente esgrafios, pues el relieve apenas profundiza algunos milímetros, el color vino a suplir estos elementos, pues se hizo de ellos verdaderas pinturas concebidas no para ser vistas contrastadas con la luz solar, sino por la luz mortecina de las teas.

Más aún, antes que la pintura resolviese numerosas difilcultades técnicns; la dinánica, el movimiento y la composición ya se habían expresado en los bajorrelieves. Quizá debilo a la plasticidad y hermosura de éstos, la pintura quedó relegada a un segundo término, encontrandosela excepcionalmente en Palenque, 'T'ikal y Laxactun. Fil relieve les brindó la oportunidad de vencer el cstatismo impuesto por la frontalidad de la estatuaria; no podriamos, hacia el siglo VI, hablar de actitdes rigiclas, sino de composiciones ricas y de acti- 
tucies rivientus y variadas. Esto no excluye el que en gelieral los artes precortesianos llegaran a un procedimiento casi académico para tratar las formas humanas, siendo significativo el que en una vasta área como es la maya, tan mal conunicada y hostil, se concibieran, tanto personajes como motivos simbólicos, con caracteres tan uniformes. P'or ejemplo, cuando es tratada la fi. gura humana si no se le ve de perfil - que es la forma que presenta menos dificultades técnicas- se le ve el cuerpo de frente y cl rostro vuelto a un lado y los pies hacia afuera; pero no es excepcional que sea visto totalmente de frente, por ejemplo en los esclavos de las estelas de Naranjo o en las deidades y sacerdotes de las estelas de Piedras Negras. Consecuentemente, para esta época la composición ha llegado a los mís libres y complejos arreglos; en el siglo VIII, Piedras Negras esculpe el dintel 3 y la estela 12: 757 y 795 ; el primero, con 15 persotiajes, y el segundo, con 8 , quizá obra de una misma mano que podrian figurar entre las mejores del Renacimiento.

ESTELAS DEL USUMACINTA Y DFL PETEN

Características y singulares de los mayas del Antiguo Imperio, verdaderos monumentos del arte, de la ciencia calendárica y de la ciencia astronómica de la vieja cultura de la América meridional. Desde un punto de vista artístico, sólo nos interesa, provisionalmente, aquel grupo de estelas en que la lápida en una de sus caras está esculpida con motivos o escenas ceremoniales -excluímos, pues, las estelas-obeliscos de Copán y Quiriguá que si arqueológicamente significan lo mismo, artisticamente tienden más a la escultura en redondo-. Son, pues, las estelas grandes lápidas monolíticas de medidas sumamente variables, pero que en la gran época corresponden a uno o dos metros de ancho por tres a cinco metros de alto y treinta a cuarenta centímetros de espesor, estando clavada parte de la lápida en tierra para sostenerla en posición vertical; la escena o el personaje, acompañado de la datación jezoglífica, aparece en una o ambas caras de la estela, estando ésta a veces esculpida aún en sus estrechos bordes del espesor. En la época de mayor esplendor, aparecen relacionadas las estelas con la arquitectura del Templo, bien una sola en la terraza o bien varias alineadas en el frente de la fachada y acompañadas siempre por altares (Yaxhilán, Piedras Negras. Naranjo, etc.) ; previamente han aparecido relacionadas $\mathrm{con}$ la arquitectura de la plaza (Copán); y todavia en un estrato más arcaico, la estela aparece aislada y sin relación a la arquitectura (Uaxactun):

¿Qué significación tuvieron arqueológicamente las estelas? Janda, que hacia 1556 vió estelas en Mayapán “desgastadas por el agua”, preguntó por 
su significado y se le respondió: "que acostumbraban erigir de 20 en 20 años, que es el número de contar de ellos, una piedra de aquellas", Landa cludaba de esta explicación por encontrarlas sólo en "Mayapán y Zilán" y no en ciudades tan impartantes como Uxmal y Chichén-Itzá; pero esta contradicción se originaba en el desconocimiento de las dos grandes épocas del desenvolvimiento maya, el del Sur o Antiguo Imperio y el del Norte o Nuevo Imperio, éste, el más reciente y de frectuentes influencias mexicanas, olvidó y dejó de esculpir estelas, quedando éstas relegadas a escasas ciudades de la peninsula (por ejemplo, Cobá, Macanxoc, Dzilan, Oxkintok, Hacienda Tabí, Xcauchican, Tulum y Cozumel). Morley se inclina por ešta tesis, opinando que las estelas se erigian para fijar o conmemorar el tránsito de unidades nayas, quizá al finalizar de cada katún. No es, pues, extraordinario que al pie de estas estelas se encuentren frecuentemente ofrendas votivas consistentes generalmente en hachas de obsidiana o sílex en formas excéntricas, y aun en Copán bajo una de ellas se encuentra una cámara sepulcral. Más aún, nuevas orientaciones nos dan las investigaciones de Blom y Ricketson, quienes han demostrado la relación de una estela de Uuxactun, coincidiendo sus aristas con las de las jambas de un templo, como líneas solares en los solsticios y equinoccios, por lo que podemos deducir en algunos casos finalidacles astronómicas.

Consecuentemente, las estelas llevan inscritas jeroglificamente la fecha de su erección, es decir, la fecha conmemorativa del tránsito de tiempo maya.

Probablemente las primeras estelas inscritas han desaparecido definitivamente debido a la naturaleza perecedera de la madera en que fueron esculpidas, o del estuco en que fueron modeladas; también probablemente estas prinieras estelas aparecen esculpidas (como sucede en Copán) únicamente con jeroglíficos, desenvolviéndose más tarde esculturas de personajes, que ya aparecen en forma groseramente trabajados en la estela 9 de Uaxtactun, 327 D. C. Spinden ha estudiado la evolución estilística de las estelas en Copán: la primera fase, desenvuelta en el siglo $\mathrm{V}$, carresponde a las estelas inscritas con jeroglificos arcaizantes en un bajorrelieve muy poco profundo, y tratados en forma grosera; la segunda fase, correspondiente al siglo VI y VII, es la de estelas esculpidas con personajes de yelmo zoomórfico, portando barra ceremonial y con los pies agudamente vueltos hacia afuera, brazos y piernas un poco rígidas, y poco estudio de las proporciones humanas, así como rostros angulosos y de nariz ancha, pero en relieve más alto; la tercera fase corresponde al siglo VIII y IX, con personajes de yelmo en forma de turbante, barra ceremonial, mascarones grotescos, ojos abultados tendiendo por 
esta época las estelas a la escultura en redondo, tratandose de verdaderos idolos de rostros bellamente modelados, de líneas suaves y flexibles, de pies con ligero vuelco hacia fuera y de gran realismo, es decir, las estelas-obelis$\cos \mathrm{A}, \mathrm{B}, \mathrm{C}, \mathrm{D}, \mathrm{F}, \mathrm{H}, \mathrm{N}$ y las bellas esculturas de los temples $11,16,22$.

En un estudio de esta naturaleza no pretenderíamos agotar el estudio de todas y cada una de las estelas dispersas en la vasta extensión del área del Antiguo Imperio, sino referirnos a las piezas maestras de este arte. Esta clase de monumentos -que en las culturas mexicanas sólo hallamos crudamente desenvueltos entre los zapotecas-- aparece en las ciudades mayas de Tabasco (Piedra Labrada, Tres Zapotes, Tortuguero, etc.), pero por su tamaño, por su tosquedad, pueden inclinainos a suponer que se trata de la cuna de ellos o de un área de expansión en época degenerativa. Curioso es señalar que una ciudad tan importante como Palenque sólo conserve una estela, sin esculpir por cierto, y no se haya practicado este arte por los hombres de esta ciudad. Por el contrario, más al sur, siguiendo la cuenca del Usumacinta, aparecen dos grandes ciudades de estelas, las más hermosas, Piedras Negras, Guatemala y Yaxchilán, Chiapas (descontando ciudades de piezas menores como el Cayo, la Mar, Chicozapote, etc). Pero es, sobre todo, Piedŗas Negras, el sitio privilegiado de este arte.

Las estelas de Piedras Negras (1), como la generalidad de las ciudades, están escujpidas con una escena que se ha señalado indistintamente como ceremonial o histórica. Cuando la estela no es jeroglífica (por ejemplo las estelas 29 y 36), sin ilegar a la belleza de los glifos de Copán o Quiriguá, aparece con un personaje que Maler supone alto jefe, Halachvinic, o bien alto sacendote, Ahuacan, teniendo generalmente a sus pies un personaje de importancia secundaria, sedente o prosternado que se ha supuesto cautivo de guerra, esclavo, o victima religiosa propiciatoria - esta clase de esclavos, en el área de Cankuen, Macanxoc y sobre todo Naranjo, aparecen tendidos al suelo, sustentándose el personaje sobre sus espaldas-. Ahora bien, estos personajes en las estelas son vistos en tres formas: - sin contar la forma simple de perfil一 el personaje de frente, excepto rostro vuelto a un lado y

(1) Pub. por Teoberto Maler: Researches in the Central Portion of the Usumatzintla Valley (1898-1900). Memoirs of the Peabody Museum. Vol. II-1 (La Reforma, Cháncala, Xnpá, Pethá, Piedras Negras). Cambridge, Mass. 1901. 
pies hacia atuera $2,4,13,32,34$; el personaje totalmente de frente, aun el rostro, y recortado éste en un óvaio que tiende al alto relieve $1,7,8,9,31$; y aquellas en que el personaje, quizá una deidad femenina, se esculpe en profundo nicho, sentada a la manera oriental y trataclo en alto rclieve, excepto el mascáón o personaje ctie fuera del nicho mira a la deidad, desde abajo, $6,11,14$, etc. Otro subgrupo lo formarian aquellas estelas que, como la 5 , 12,15 y 33 dan origen a una verdadera escena.

Una de las más bellas piezas es la número 13 (771), desgraciadamente nuy fragmentada. presentándonos un alto personaje con elaborada cesta en la mano en actitud de arrojar granos de maiz en el stielo; el personaje suavemente se inclina, con natural movimiento, apareciendo vestido con el rico $\mathrm{y}$ vistoso traje de la Gran Epoca Naya. Otros dos ejemplares que podríamos considerar de los más representativos son la 11 y la 14 a ambas representando deidades femeninas?, sentadas con las piernas cruzadas y recortadas en alto relieve en un nicho en la parte alta, tocadas de yelmos de nascarones grotescos $y$ ataviadas con collares, pulseras, etc; todo el marco de la estela que rodea a1 nicho decoran glifos, máscaras o entrelaces caprichosos, y aún personajes que miran a la deidad. Recientemente se ha descubierto, después de la exploración de Satterwaite, una nueva estela, la número 15 , con una deidad hincada en lo alto y arrojando maíz de arriba a abajo, a la tierra, que se representa por uil mascarón que surge del suelo. Pero la pieza indiscutibiemente más valiosa es la 12, encontrada por Maler en cuatro fragmentos (actualmente obra en el Museo de Filadelfia de donde pasará al Museo Arqucológico de Catatemala): la escena es de las piezas más notables por sat realisno, por su composición y por su movimiento: en lo alto, sentado en hermoso trono $y$ dejando caer una extremidad, el personaje principal portando cnorme lanza ritual y vistiendo elaboradamente; a ambos lados, $y$ en el stelo, otros dos gucreros cle importancia secundaria conduciendo un grupo de esclavos atados, esculpidos con gran fineza y realismo, denotando estos su calidad inferior no sólo en la indumentaría sino en el tipo físico; ellos aparecen en el suelo arreglados cuatro en la primera linea del suelo, dos en la parte central $y$ uno en la línea superior, a 10:5 pies del Gran Sacerdote o Jefe Suptemo; esta preciosa obra ld arte de Piedras Negras fué esculpida en 775.

De Yaxchilán (1) pocas estelas han llegado a nosotros en regular estado de conservación y ninguina de ellas tratadas con la finura de las

(1) Pub. por Teoberto Maler: Researches in the Central Portion of the $U_{\text {stamatzintla }}$ Valtey (1898-1900). Memoirs of the Peabody Museum. Vol. II-2 (El Cayo. Budsilha. la Mar, El Chile. Anaité II. El Chicozapote. Yaxchilán. San Andrés Bolón. San Lorenzo). Cambridge, Mass., 1901. 
estelas de Piedras Negras. Una de las más interesantes es la estela 11, frente a la estructura 40. Ambas caras están tratadas en un profundo relieve; en el lado frontal se esculpieron dos altos guerreros, de igual rango aparentemente, pero uno vistiendo con más riqueza, portando espaldar de pluma y escudo circular de mascarón. En la cara posterjor aparece un personaje que emptuña cetro y viste elaborada indumentaria, en actitud de humillar a tres cautivos que aparecen arrodillados a sus pies.

Dos ciudades de la cuenca superior del Usumacinta, en Guatenuala, son de fundamental importancia en el arte de las estelas, Seibal y Cankuen. (1) La estela 10 de Seibal es uno de los ejemplares más barrocos, más cercanos a la época de disolución del Imperio Maya del sur, de cuantas se conocen. Lleva inscrita la fecha 849 de nuestra Era, y en el diseño elaborado acusa agudamente el "flamboyancy" de la última época. "Trátase de un personaje, visto en el frente-perfil mencionaclo, vistiendo una indumentaria riquisima, del más complicado yelmo y más fastuoso penacho, colgando en las manos una barra ceremonial de cuyos extremos surgen virgulas serpentinas isimholos del fuego? que en un extremo caen al suelo $y$ en el otro se flevan a la parte alta.

La otra ciudact mencionada, Cankuen, aporta un tipo de estela que en Varanjo llegará a sus más preciosas realizaciones, aquella en que el personaje se sustenta sobre las espaldas de la víctina caída en el suelo. El personaje se encuentra en actitud de danzar, alzánclose sobre la punta de los pies $y$ flexionando ligeramente las rodillas, sobre las espaldas del cantivo (esta actitud es mty semejante a la de la esteh de Motul de San José, sólo que en ésta se trata de dos personajes, pero no sobre personajes humanos).

Quedan por mencionar las ciudades de Petén Guatemalteco, Laxactun, Tika! y Naranjo, principalmente, y açuellas que fuera de esta área gitardan estrechas relaciones con ella, Ixkun, Guatemala y Calakmul. Campeche. Fin realiclas. Laxactun (2) tiene para nosotros un exchusivo interés arrucológito en este aspecto, bien porque sus hombres no llegaran a refinadas concepciones artísticas, bien porque el tiempo ha destruido sus estelas y wo tienen

(1) Pub. por Teoberto Maler: Exploration of the Upper Usumatzintla and Adicent Region (Altar de Sacrificios, Seibal. Itzimte-Sacklau. Cankuen). Memoirs of the Peabody Museum Vol. IV-1. Cambridge, Mass.. 1908.

i2) Pub. Thomas Gann. 
para el arte un interés primordial. En 'Tikal (1) se opera el mismo fenómeno, aunque en este caso resten estelas parcialmente destruídas, cono la número 5, o bastante conservadas, como la 16 , que nos permiten juzgar del alto valor plástico de los constructores de las impresionantes pirámides y exquisitos relieves de los dinteles de madera.

En Naranjo, (2) las estelas vuelven a tener un brillo y esplendor extraordinarios. El carácter relevante de estas estelas deriva fundamentalmente de los esclavos o víctimas sobre las que se sustenta el personaje principal, visto siempre en el frente-perfil de los mayas, como en la hermosa estela 8 (muy próxima a la estela del mismo número de Seibal), portando preciosa lanza ritual. No en todos los casos el personaje se sustenta sobre el vencido, pues no es excepcional el que se yerga de mascarones fantásticos o directamente del suelo; pero cuando aparece sobre las espaldas de un cautivo, éste se le ve en las más ricas y variadas actitudes, no siendo excepcional que el rostro. del mismo sea tratado esculpiéndolo de frente-este hecho es sufícientemente ilustrativo-, mientras al personaje principal, por un trato atávico, se vuelve el rostro de un lado y se vuelcan los pies a ambos lados, en rigido ángulo, quizá debido a una absurda estilización académica, los esclavos se les ve arrodillados (estela 19), tendidos a lo largo y con la cara al suelo (estela 23), con el pecho al suelo y rodillas ligeramente flexionadas y manos atadas en la espalda y levantando ligeramente el rostro (estelas 8 y 12), así como tres estelas $(14,21$ y 24 ) en que el personaje dobla el tronco y vuelve s11 rostro de frente, siendo expresivamente terrible el rostro del cautivo de la estela 21 y singularmente naturalista la de la 24 , en que el vencido recarga su rostro sobre uno de sus brazos en actitud muy semejante a la de quien va a dormir, siendo esculpidos con gran realismo los detalles de su rostro aplastado al recargarse en uno de sus brazos.

Restan par mencionar dos ciudades fuera del área del Petén, Ixkün en Guatemala y Calakmul en Campeche.

La estela más importante de Lxkun,(3) dada a conocer por Maudslay, es una de las lápidas monolíticas más grandiosas del área maya; en ella se

(1) Pub. Teoberto Malex: Exploration of the Department of Peten, Guatemala. Tikal. Memoirs of the Peobody Museum. Vol. V-1. Cambridge, Mass., 1911.

(2) Pub. Teaberto Maler: Exploration in the Department of Peten, Guatemala and Adjacent Region. (Tepoxté, Yaxbá, Benké Viejo, Naranjo). Memoirs of the Peabody Museum. Vol. IV-2. Cambridge, Mass., 1908. $1895-1902$.

(3) Pub. A. P. Maudslay: Biologia Centrali-Americana... Archeology London 
esculpieron, sobre un banco de glifos-que encierran en cada uno de sus ángtulos, personajes inferiores sentados en actitud de levantar una de las extremidades-dos personajes principales, portando báculos ceremoniales, frente a frente, una actitud similar a la de la estela 11 de Yaxchilán, ya mencionada.

De importancia también capital debió haber sido en los siglos VII y VIII la ciudad de Calakmul, (1) al sur de Campeche; pero desgraciadamente, del ciento o más estelas-la más rica ciudad en estelas-, son excepcionales las que hạ podido conservarse hasta nuestros dias, particularmente la estela 51, que podríamos considerar entre los más bellos ejemplares del arte de los mayas, asi por la fineza y profundidad del dibujo en relieve, como por la riqueza de su indumentaria; siendo esculpida esta estela en el siglo $V I I I$ de nuestra Era, hacia 731, D. C.

ALTARES

De similar importancia, en la arqueologia artística maya, son los relieves de los llamados altares. Son éstos piedras monolíticas de forma generalmente cuadrangular o circular-no son, sin embargo, extrañas las mesas de soportes glíficos o de mascatones, como en Piedras Negras y en Copán, o bien los bloques irregulares afectando formas zoomórficas, como en Quiriguá y Copán--. Stephens fué el primero en llamarles altares: "Pero no nos queda duda de que la piedra esculpida que invariablemente se ve frente a cada ídolo (estela), se empleaba como altar de sacrificios", quizá, añadiríamos, si no de sacrificios, si del ceremonial.

Copán (2) es la ciưad más rica en ejemplates de esta naturaleza. Pero, a semejanza de las estelas, los altares también tienden más a la escultura

(1) Pub. S. G. Morley: The Calakmul Expedition (The Culture of the Maya). Carpegie Institution of Washington. 1933.

(2) Pab. Alfred P. Maudslay. Ob. Cit. 
que al relieve. Desconocemos los altares primitivos de esta cirdad, bicn por haberse perdido o bien por haber sido trasladados o aprovechados coms naterial en épocas posteriores. Del siglo VI se tienen los prinetos altares trajajados en bloques rectangulares o en piedras circulares (Altar I), invariablentente esculpidos con bandas jeroglíficas; hacia el siglo VII se empiezan a esculpir los primeros altares zoomórficos (jaguares, tortugas, dragones o monstruos fantásticos, serpientes de doble cabeza, etc.), $y$ los altares con el mascarón de la muerte, altar D, F, H, G1, M, N, O, U; desenvolviéndose, inicialmente, el culto simbólico de la serpiente, como vemos en el reptil manchado y crestado de plumas pequeñas del altar $O$, o en el bellísimo altar G1 de la serpiente de doble cabeza, ¿xiuhcoatl?, cuyo cuerpo se alza en forma cle herradura.

Pero para el relieve nos interesan fundanentalmente dos piezas: los altares $Q$ y $T$. El primero es un bloque rectangular esculpido en sus cuatro caras con personajes sentados en diversas posiciones, tocados de bellos turbantes, que los acercan al basamento del 'Templo 11 ; esta pieza se esculpió hacia 776 y parece desenvolver una escena ligada con un suceso astronónico. El segundo de estos altares, el altar $\mathrm{T}$, es bastante similar en los motivos que lo exornan, sólo que en este caso entre los personajes esculpidos aíternan deiclades o sacerdotes de máscaras zoomórticas.

Quiriguá (1), ciudad relacionada con la última época de Copán, desenvuelve igualmente en alto grado el alto relieve y la escultura, así en sus estelas como en sus aitares. En especial cobran formas grandiosas los aitares zoonórficos, siendo piezas ejemplares el monstruo B, el jaguar $\mathrm{G}$ (780). pero sobre todo el ciclópeo altar P, llamado de la Gran Tortuga (785), el más grandioso de los monumentos mayas, representando un monstruo mitológico en actitul recogida, teniendo esculpida en stt cara norte una figura humana sentada a la manera oriental y trabajada en alto relieve-este altar fué esculpido en compacta piedra arenisca, siendo uno de los más grandiosos monolitos, pues mide $2.21 \mathrm{~m}$. de largo, por $2.95 \mathrm{~m}$. de ancho y $3.50 \mathrm{~m}$. de altura.

Desde el punto de vista del relieve son importantes dos altares: el altar circular esculpiclo con una cliosa sedente y encerrada por un anillo de glifos; y el altar recientemente descubierto (2), el del Dios Danzante, "el más bello

(1) Pub. Alfred P. Mandslay. Ob. Cit.

(2) Pub. Sylvanus G. Morley: Guide Bonk to the Ruins of Quirigua (Carnegie (nstitution of Washington). Washington. 
montmento de su clase en la región maya", representando un bailarín, esculpido en un relieve tan profuncio que a veces penetra hasta quince centímetros de la superficie, llevardo el danzante una máscara atada al dorso de su brazo (790).

Continuando nuestro propósito de no perseguir un estudio exhatustivo de todos los altares y ciudades mayas, queda por referinos a algunos cjenplares del Petén y del Usumacinta. Mencionaremos a Benké Viejo, Belic, cuyo altar decora un sacerdote semi arrodillado encuadrado por marco jeroglífico (1) ; a Altar de Sacrificios por conservar el primitivo tipo de aitar circular esculpido en su borde antlar por glifos (2); a Yaxchilán, Chiapas, por conservar innumerables altarcillos circulares seccionados en forma que recuerdos los mosaicos de Chichén Itzá (3); a Piedras Negras, cuyos alta. res se tornan verdaderas mesas sostenidas por pilastras jeroglíficas o por soportes en forma de mascarón (4); a Chajcar, donde Lothrop descubrió un fragmento de altar esculpido con la más bella estilización conocida del peșcado (5) ; y sobre todo Tikal, donde Maler descubrió ftente a la estela 16 un altar circular esculpido con una de las escenas más bellamente realistas del Antiguo Imperio (6). trátase de un altar circular, un metro sesenta y ocho centimetros de diámetro y treinta y seis de espesor, decorado en su cara superior por dos sacerdotes mayas, tocados del turbante que hemos considerado de tipo chinesco, en bella actitud, arrodillados, y portando objetos rituales mirando a un cráneo, simbolo de la nuerte, que aparece en el suelo y al centro.

Podriamos separar dentro del grupo de altares, los altarcilios circulares marcados del juego de pelota recienteinente descubiertos e identificados-rectérdese que el propio Clavijero habla de piedras marcadioras--, por ejempio en Copán, Cankuen, Jubaantun y Chincultik, cuyos altares servían para dividir en cuarteles el campo del juego. Ei más inportante de ellos es el de Chinctiltik, Chiapas, actualmente en el Museo Nacional de México, esculpido

(1) Pub. Teoberto Maler: Ob. Cit, Vol. IV.-.2

(2) Pub. Teoberto Maler: Ob. Cis. Vol. IV-l.

(3) Pub. Teoberto Maler: Ob. Cit. Vol. I-2.

(4) Pub. Teoberto Maler: Ob. Cit. Vol. II-.l

(5) Pub. S. K. Lothrop.

(6) Pub. Teoberto Maler: Ob. Cit, Vol. V-1. 
con un sacerdote jugador de pelota que aparece en actitud de arrojar con su cuerpo una enorme bola ritual, estando encerrado por un friso anular jeroglífico en el que se consigna una fecha, posiblemente recordatoria, 592 de nuestra Es.ra. (M, Mariscal).

BASAMENTOS, MLROS, TABIEROS

No son escasos los ejemplos de muros, basamentos, peldaños y dinteles, tableros, esculpidos por los mayas, quienes, como hemos apuntado, rehuyeron en lo posible los espacios vacios y procuraron recargar de ornamentos los sitios más visibles. Originalmente este espíritu ornamental usó ampliamente del modelado en estuco, como se observa en el más viejo de los monumentos mayas, en la pirámide E VII Sub de Uaxactun, ligada con la estela 9, de 327, de nuestra Era; con el Nuevo Imperio casi desaparece este tipo de decoración, tan ustal en la Gran Epoca de Palenque y Tikal, substituyéndose por la ornamentación en relieve escttpida en piedra, pero desenvolviéndose inicialmente en las ciudades del sur, tímidamente en Palenque y en forma franca en Copán.

La primera ciudad, que desvió su atención fundamentalmente al modelaclo en estuco, no carece de bellos ejemplares esculpidos. En el Palacio, por ejemplo en los basamentos de los templos A y C, así como en las alfardas, decoran monumentales personajes de un estilo muy primitivo. Pero Palenque no carece de bellos relieves empotrados en sus muros verbi gracia el de la Casa $\mathrm{E}$, notable por su trono de jaguar de doble cabeza en el que está sentado el sacerdote o personaje al que ofrenda una mujer del pueblo (1). Otro ejemplar de esta clase es la magnifica pieza del Museo Arqueológico de Madrid (una lápida de cuarenta y un cestímetros por veintiocho de ancho), esculpido en forma realista con un maya, vestido con la usual sobriedad de esta ciudad, sentado en un taburete y colgando una de las extremidades, portando en sus manos una bella estilización de flor campanulada (2).

(1) Pub. A. P. Maudslay: Ob. Cit

(2) Pub. Henri A. Lavachery: Las artes antiguas de América en el Museo Arqueológico de Madrid. Amberes, 1929. 
Pero son los tres tableros: el del Sol, el de la Cruz y el de la Cruz Enramada-por haberse encontrado empotrados en los muros de las pequeñas capillas interiores de los tres templos a los que dieron nombre, podríamos considerarlos verdaderos retablos-, las piezas que más renombre han dado a Palenque. Las tres están esculpidas en un relieve poco profundo, por to que el acabado policromo las acercó más a la pintura en piedra que al relieve. Las tres son de una composición muy similar: dos sacerdotes en posición de ofrecimiento a un motivo central, el mascarón del sol sostenido por dos atlantes en el primer caso (691 D. C.), y en el segundo y tercero, el árbol de la vida en representación cruciforme, simple y foliada, significando el árbol de la vida surgiendo del mascarón de la tierra y en el cual posa el ave solar, el quetzal (1). Al retablo de la Cruz, actualmente en el Museo Arqueológico de México, lo completaban a ambos muros de la entrada de la capilla, el relieve del brujo y el del sacerdote, ambos actualmente en la iglesia de la cercana población de Palenque.

Pertenecientes a la misma escuela de Palenque, distintiva por la economía de sus formas, por el realismo y sobre todo por la sobriedad de la indumentaria, podríamos considerar el fragmento de relieve de Jonuta, Chiapas, del Museo Nacional de México, esculpido con el sarcedote ofrendante acompañado del quetzal, el ave del sol, $y$ de un símbolo fálico; también podriamos incluir el tablero de Finca Encanto, Chiapas, dado a conocer por Blom (2), que es particularmente importante por constituir el tránsito del esgrafío al relieve. pues verdaderamente se ha dibujado el contorno de dos deidades o sacerdotes uno de los cuales se dirige al otro que permanece inmóvil frente él, llevando aquél la característica barra ceremonial de los mayas del sur.

La otra zona de importancia en este capítulo es, en el otro extremo, Copán. Esta ciudad reviste particular importancia por la belleza, el realismo, el clasticismo de sus relieves y esculturas de los templos $11,16,20$ y 22.

El basamento del Templo 11 (3), hoy en el Museo Británico, es uno de los más finos relieves de los mayas. Todo el peldaño está decorado con diez

(1) Pub. A. P. Mandslay: Ob. Cit.

(2) Pub. Frans Blom: Notes from the Maya area (American Anthropologist. Vol. 26). Menasha. Wis., 1924.

(3) Pub. A. P. Maudslay: Ob. Cit. 
personajes, divididos por columna jerogiffica central hacia ia cual vuciven todos la vista; si esta pieza no la consideráramos bella por la esplendidez de la indumentaria y tocados, por el realismo del medio relicve, deberianos considerarla por la variedad y riqueza cle las actitudes de los personajes sedentes: en forma oriental, coigando una de las extremedidades, a la manera enropea, etc. Esta pieza fué esculpida en siglo VIII.

Otro de los relieves de Copán que podriamos considerar entre las oiras nuestras de los mayas, es el derredor clel pórtico del Templo 22. El basamanto jeroglífico remata en ambos extremos por dos gigantescos mascarones del dios de la muerte, tratados en altorrelieve, sobre los cuales aparecen sedeites $y$ vistos de frente clos atlantes que sostienen un festón serpentino entre cuyas virgulas aparcen diosecillos mayas — más aun, esta ciudad tendió frecuentemente no sólo al altorrelieve sino a la escultura de bulto en la ornamentación. como lo vemos en las cabezas, deidades, zomorfos, de los templos $16,20 y$ 22, piezas transladadas a Cambriłlge, Londres, etc--.

DINTELES Y PEIDANOOS DF,

MACTILAN I PIEDRAS NEGRIS

Suntuosas y llemas de nraguificencia debieron ser Yaxchilán y Piedras Negras, en la cuenca del Lisumacinta, entre los siglos VII y VIII de la Gran Epoca. Su belleza se originaba en parte muy principal en la belleza de sis estelas y de sus dinteles, así como en la riqueza de la indumentaria, ya que, a diierencia de Palenque, en especial Yaxchilán, elabora los más suntuosos tocados y las más bellas túnicas femeninas.

Los dinteles de estas citudades, trabajados en piedra caliza generalnente: de grano muy fino, acabadas con policromía, fueron concebidos no para ser vistos en el exterior de la puerta, sino en lo alto del pórtico, en el umbral, pues en las anchas y largas lápidas que atravesaban en la puerta, la cara que miraba hacia abajo de la entrada, era seleccionada para esculpirse en ella la escena del dintel-tipo semejante de pieza es el dintel del Akadzib en Chichén Itzá-. Las escenas, como en todo el arte maya, son rituales y jerogiiuicas, no faltando algunas de franco caricter histórico. 


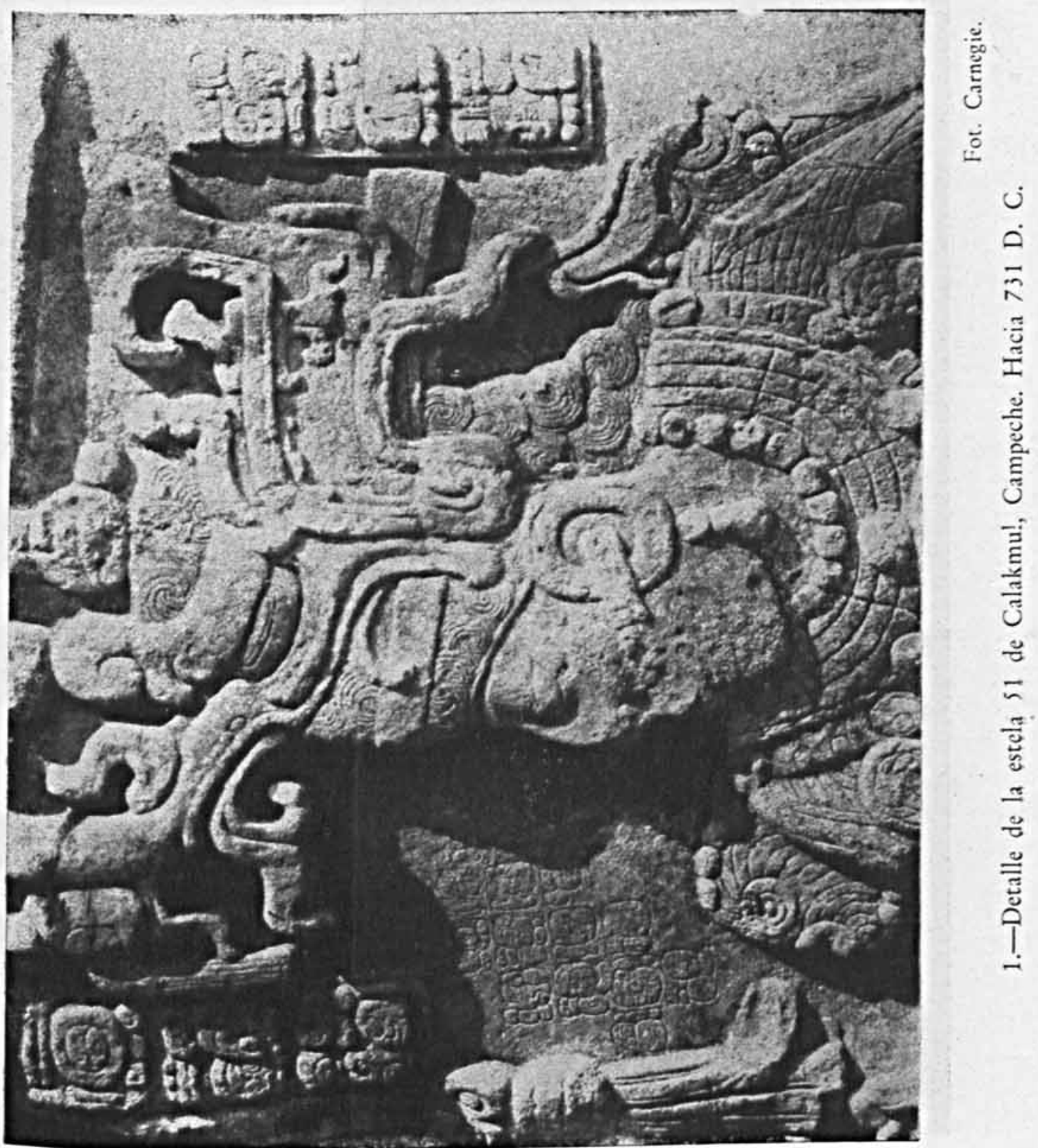




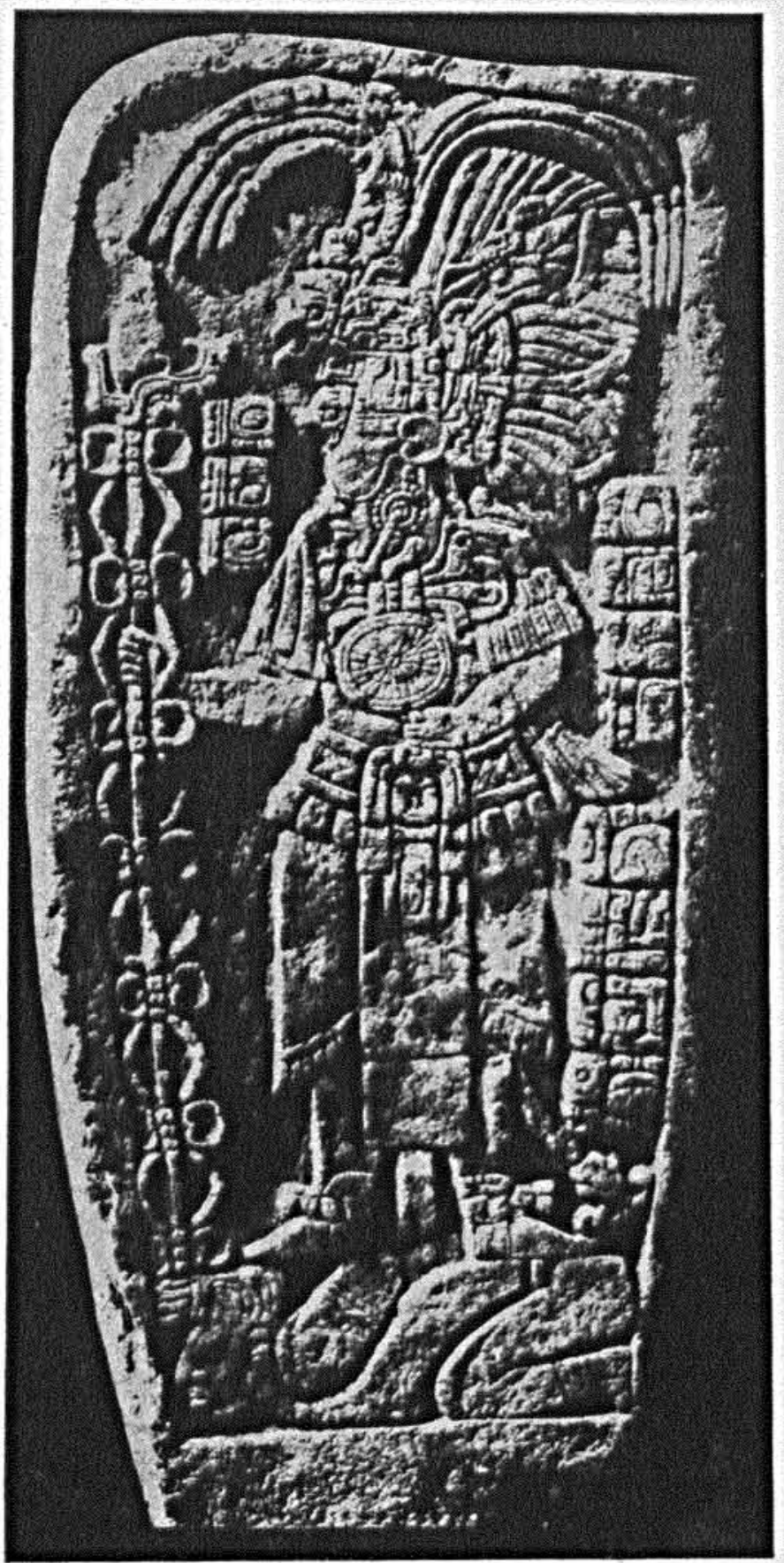

2.-Estela de Seibal, Guatemala.

Fot. Maler. 


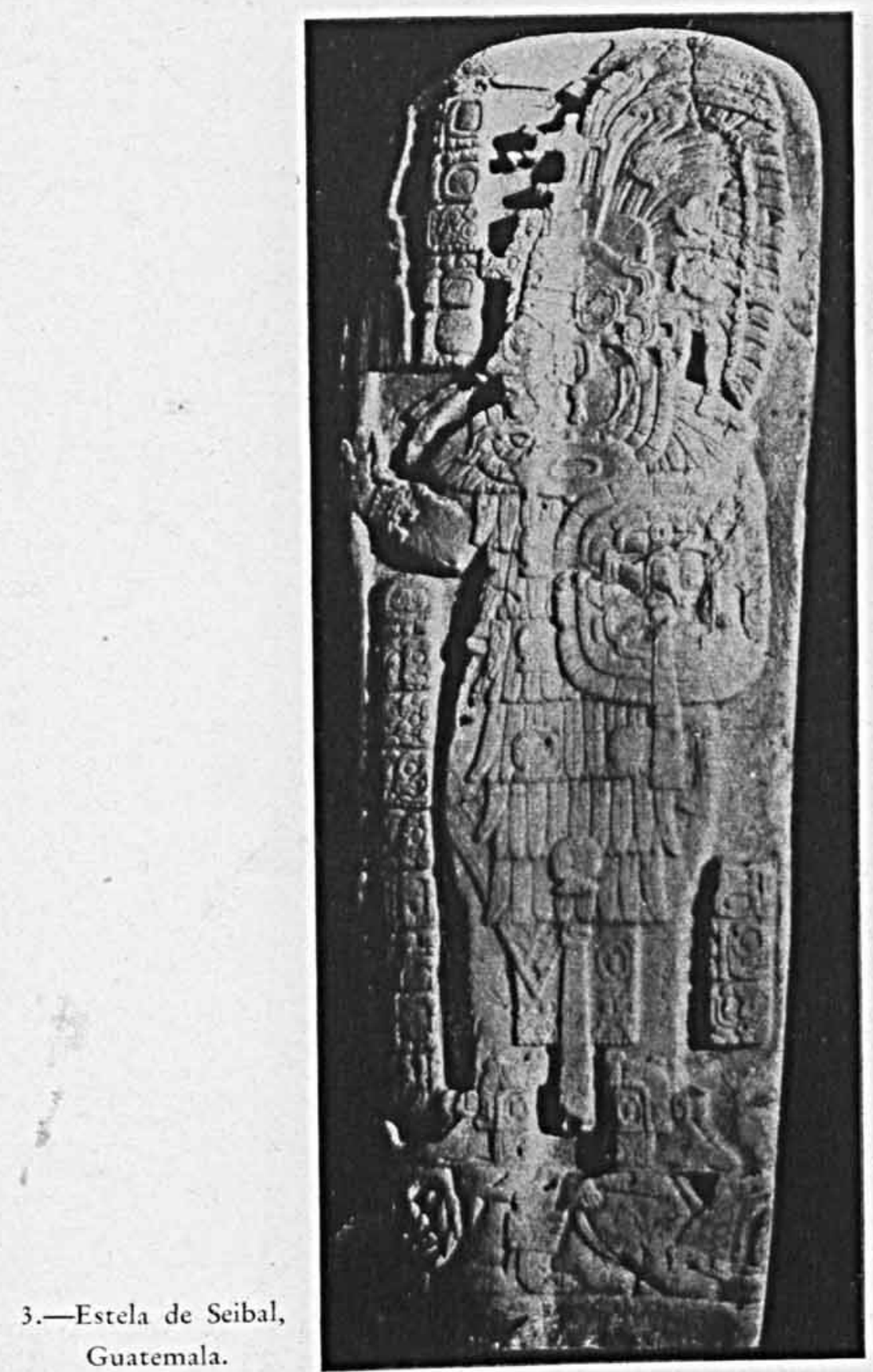

Fot. Maler. 


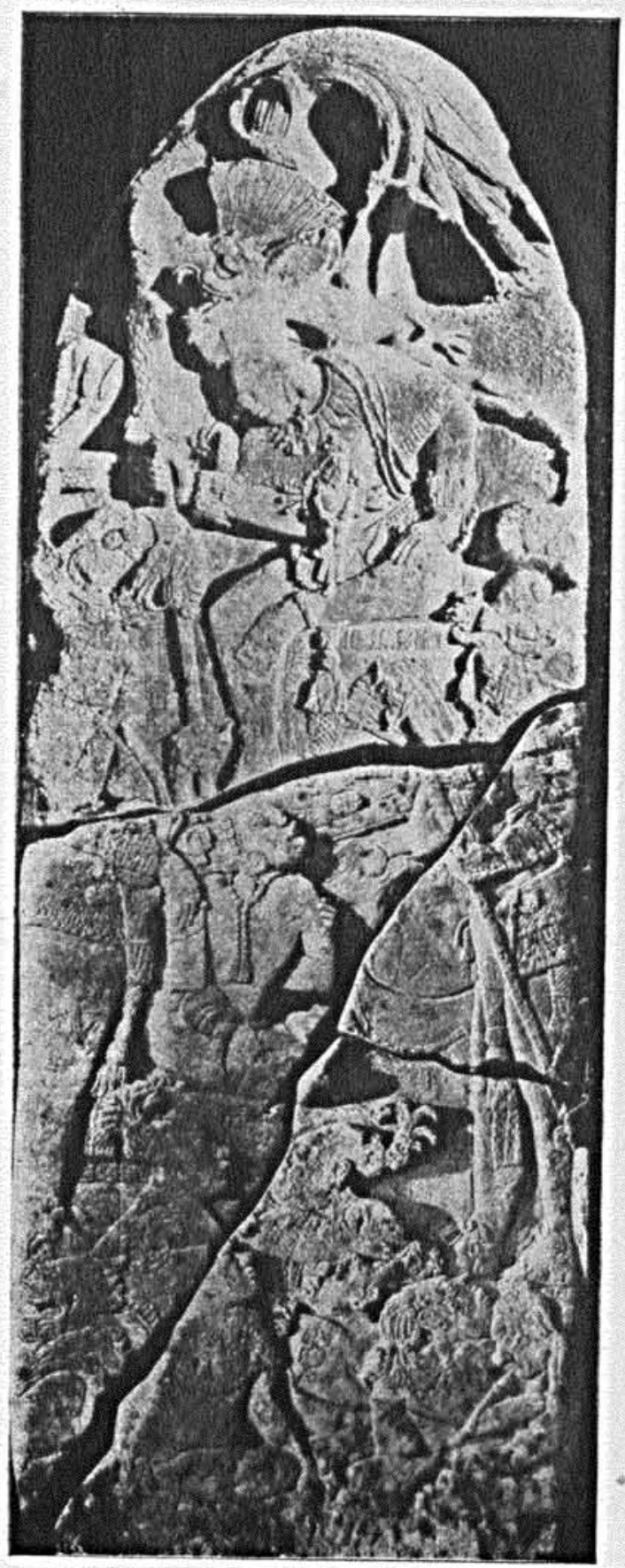

4.-Estela 12 de Piedras Negras, Guat. Hacia 775 D. C. Museo Universitario de Filadelfia.

Fot. T. Maler. 


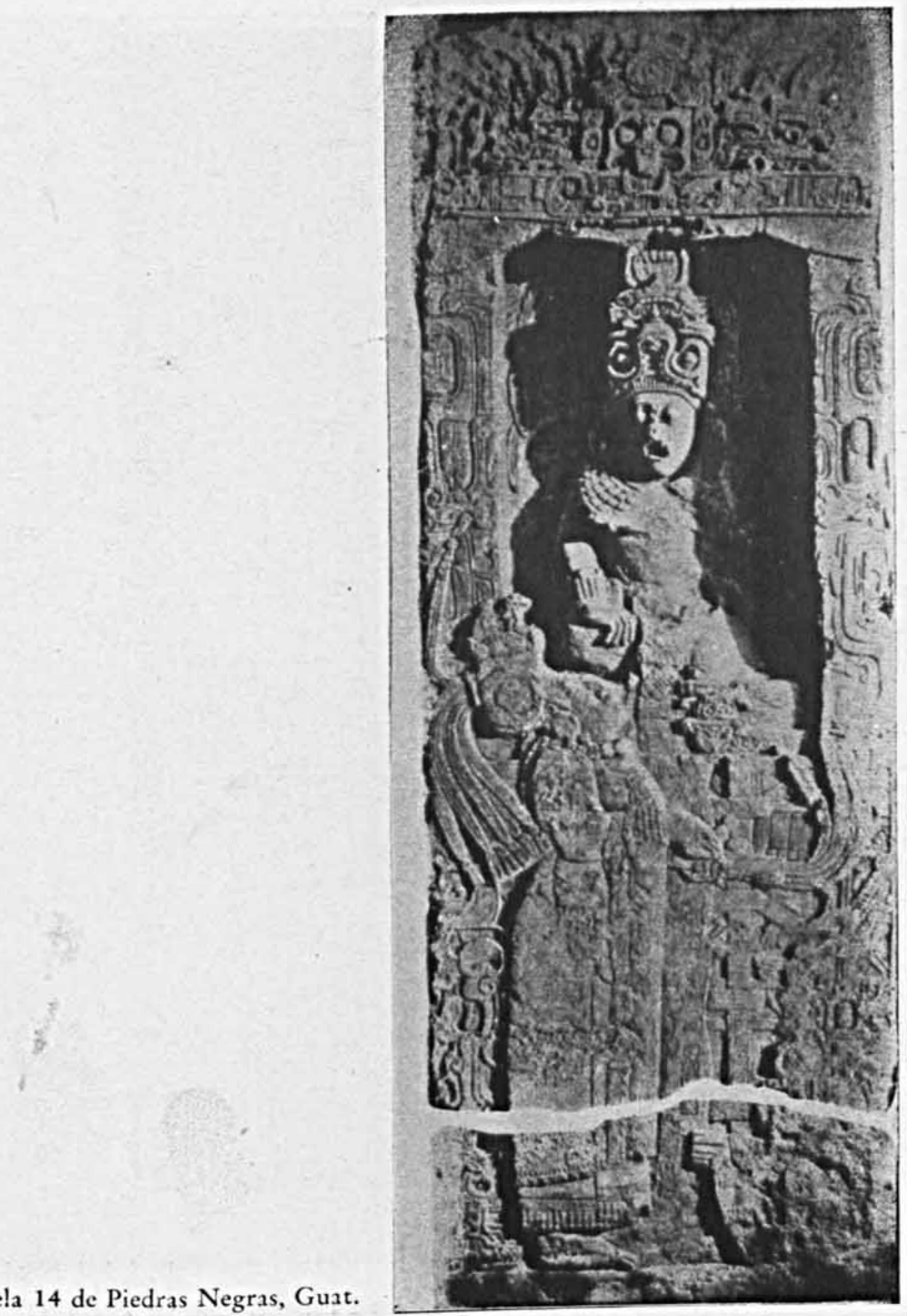

5.-Estela 14 de Piedras Negras, Guat.

Fot. T. Maler. 


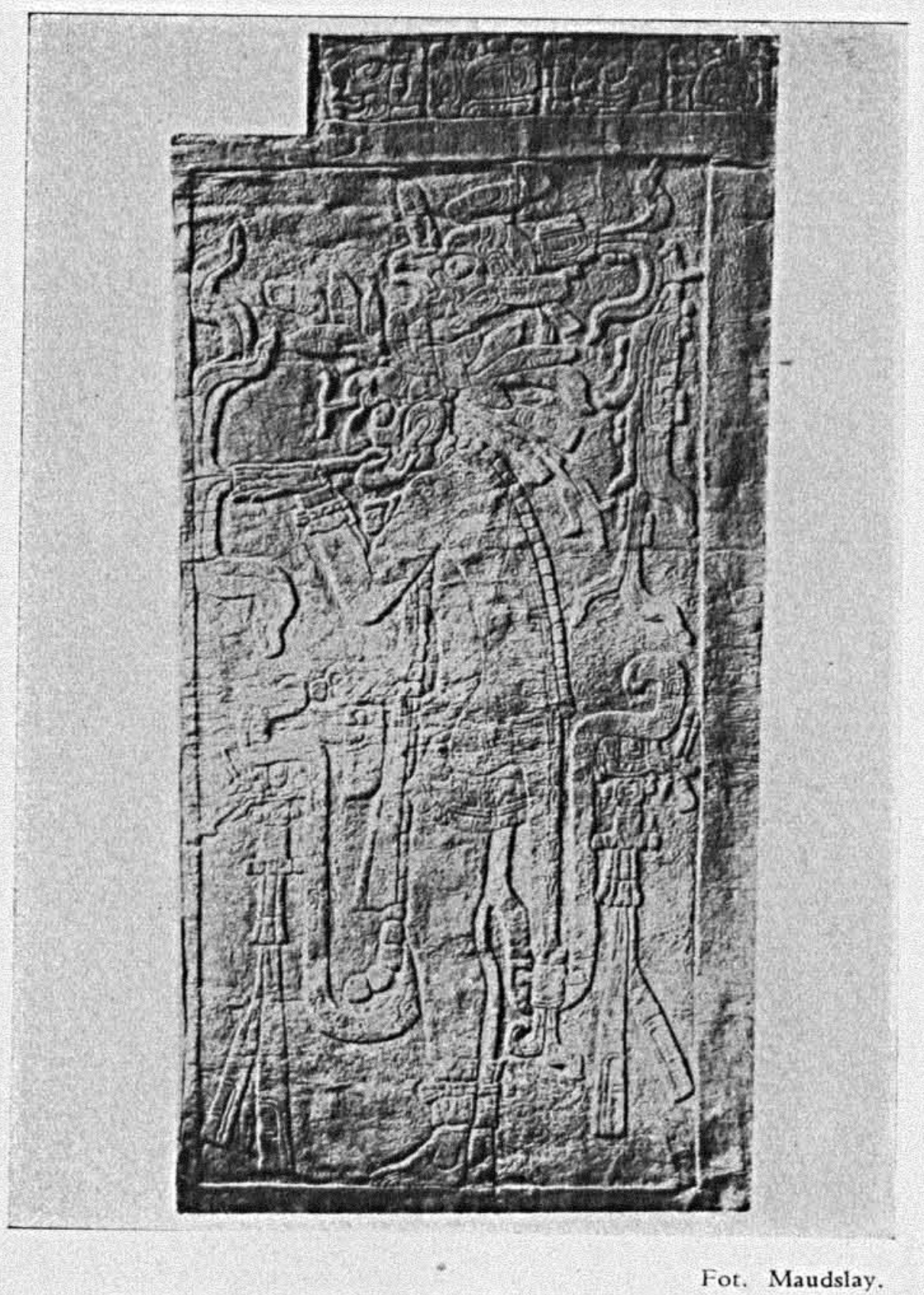

6.-Brujo de una de las capillas de Palenque, Chiapas, Siglo VII. 


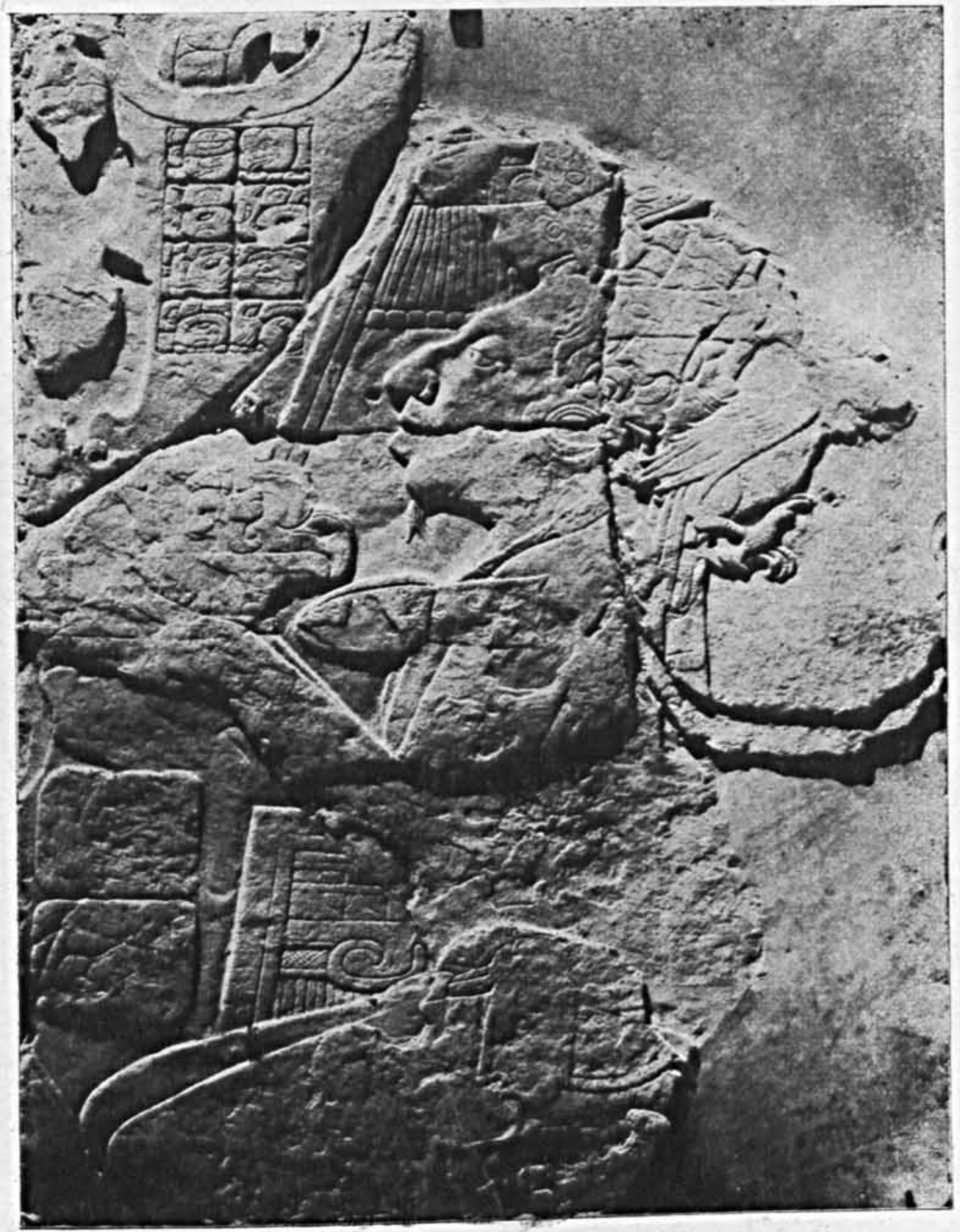

7.-Fragmento de un relieve de Jomrta, Chiapas. Museo Nacional de México. 


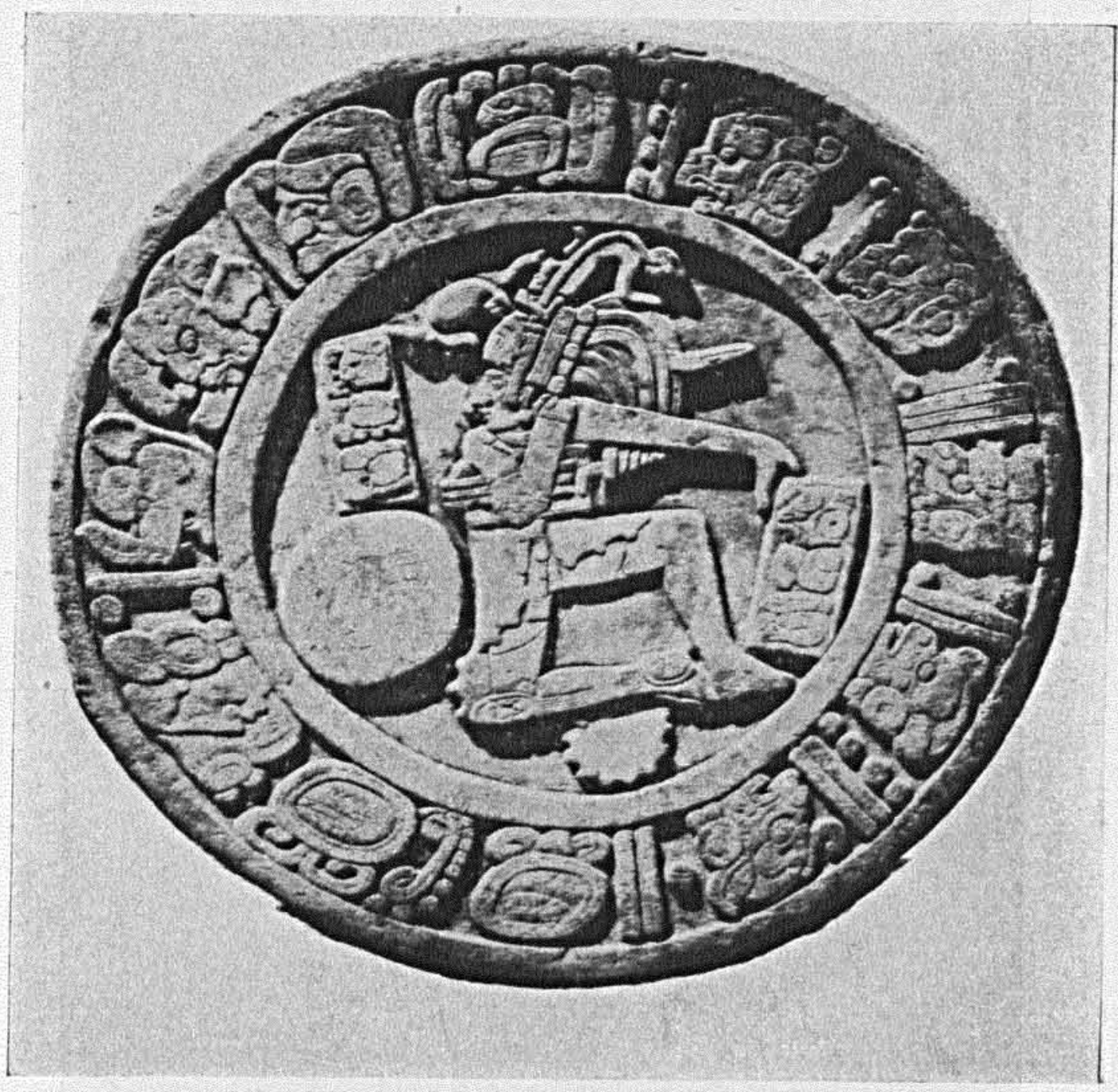

Fot. I. de A. e H. 8.-Altar marcador del Juego de Pelota. 592? D. C. Chincuiltick, Chiapas. Museo Nacional de México. 


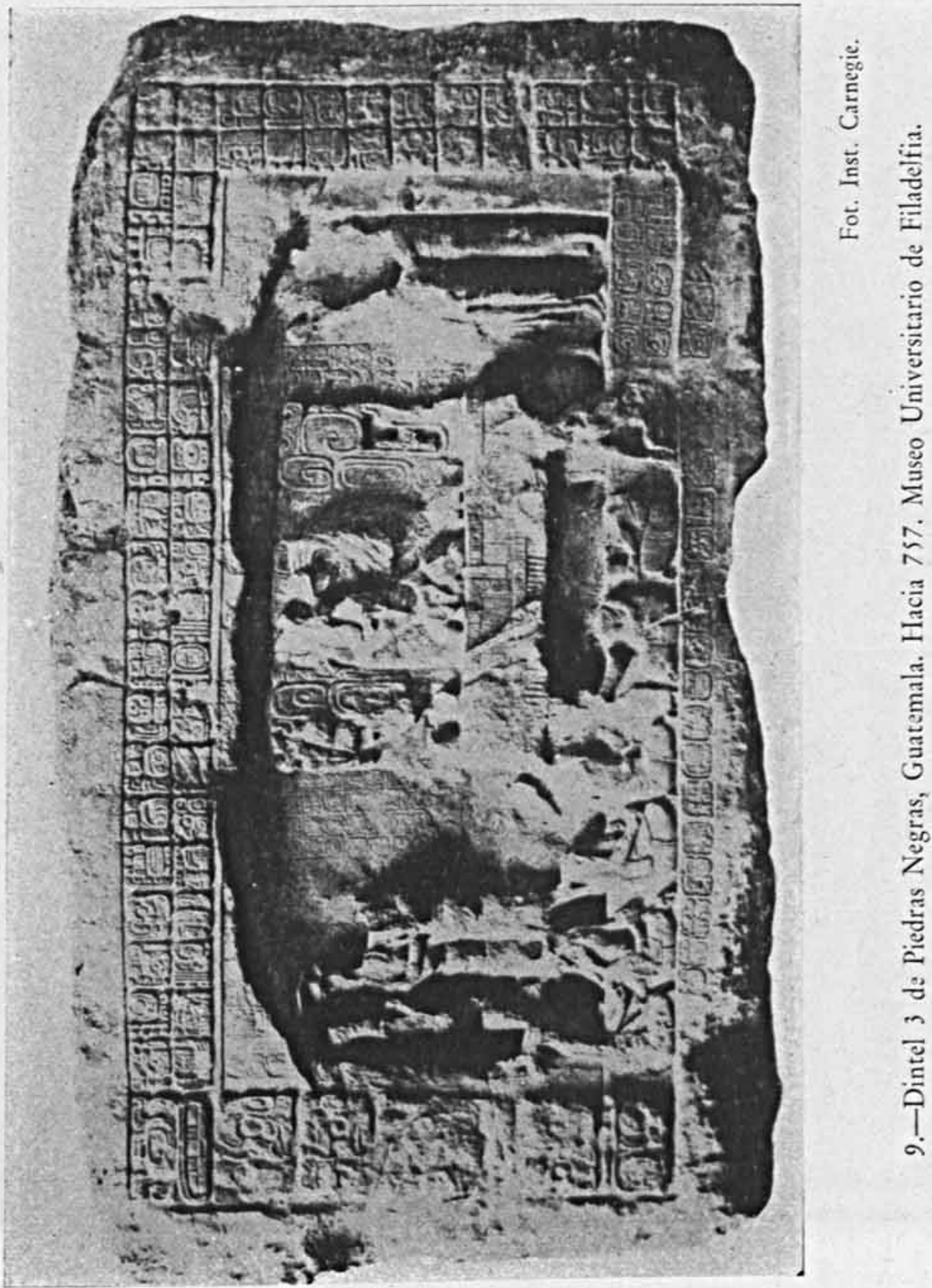




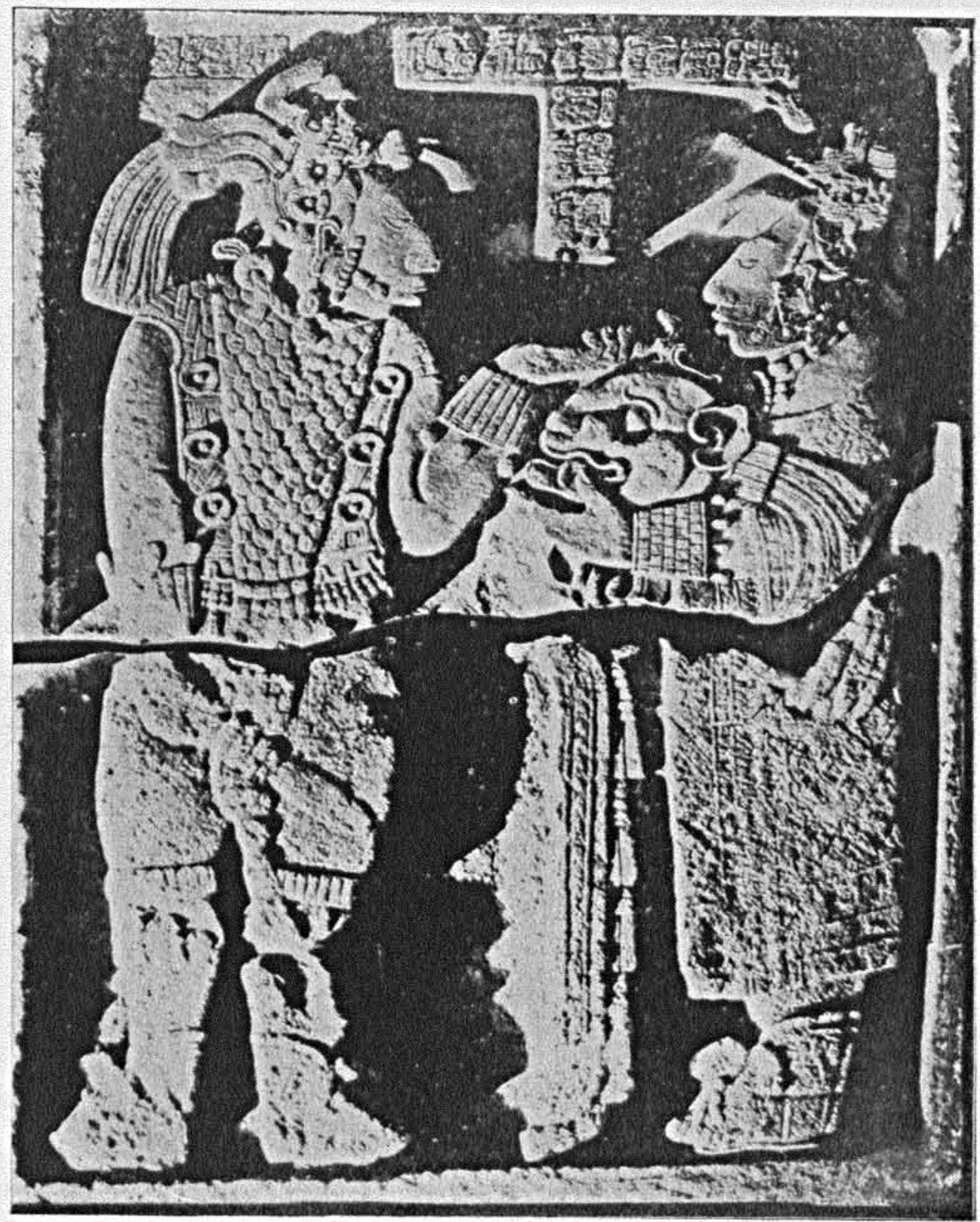

Fot. Maler.

10.-Dintel 26 de Yaxchilán, Chiapas. 


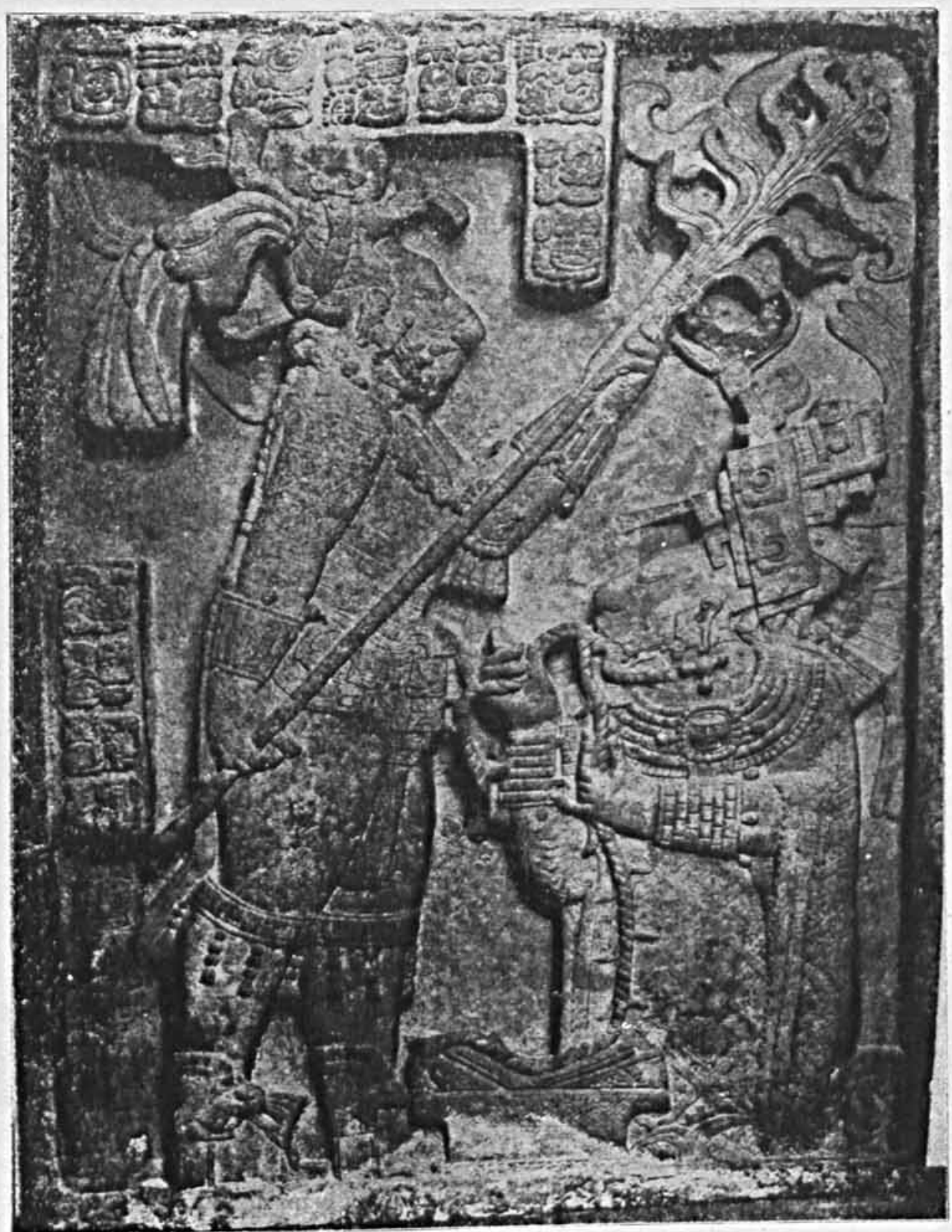

Fot. Maudslay.

11.-Dintel de la Casa G. Museo Británico. 


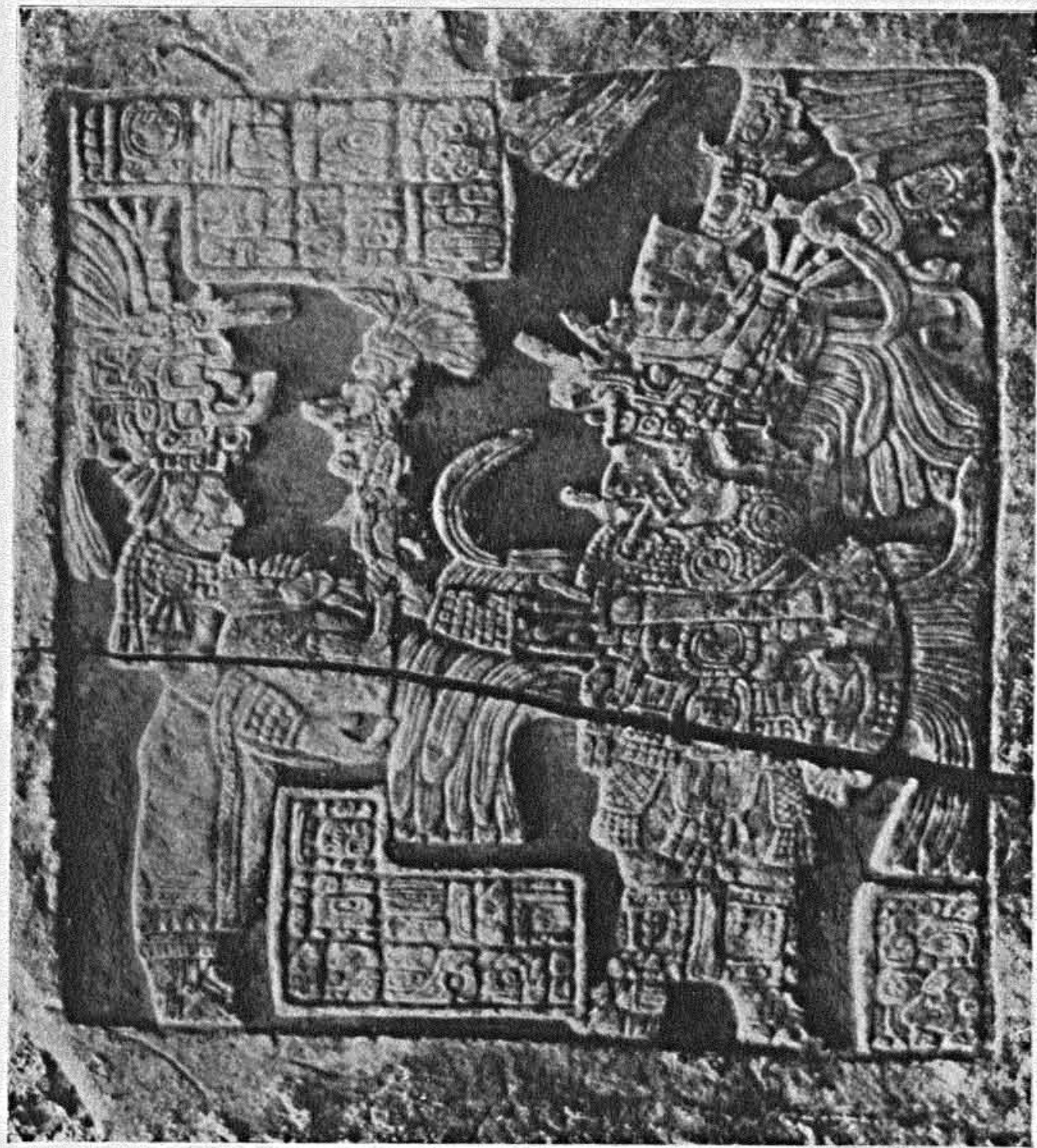

Fot. Inst. Carnegie.

12.-Dintel de Yaxchilán, Chiapas. 
Es Yaxchilán la ciudad más rica en dinteles del área maya (1)-infortunadamente los dinteles de Tikal fueron trabajados en madera, habiendo casi desaparecido para nosotros-. Maudslay trasladó al Museo Británico algunas de las más bellas piezas de Yaxchilán, entre otras las cuatro de la Casa F. El primero de los dinteles esculpido con dos figuras, aparentemente femeninas, frente a un altar de jeroglíficos entre cuyos entrelaces caprichosos surge el rostro de una deidad; el segundo con una mujer sentada en tierra ofreciendo un canasto de ofrendas a una deidad que surge de las fauces de una enorme serpiente ondulante; el tercero, esculpido con una personaje de rango cuya lanza cae en las espaldas de un personaje inferior, hincado en tierra que parece significar cattiverio; $y$ el cuarto tuna escena de autosacrificio en que una levota se atraviesa la lengua con un cordel frente a un sacerdote sentado en trono a la manera oriental. Otros de los más bellos dinteles, igualmente en el Museo Británico, son los de la Casa G ; uno representa a un jefe sacerdotal portando el bordón flamigero, en actitud de caminar frente a otra devota que practica el antosacrificio en la lengua; $y$ el de la serpiente ondulante en cuyas fauces surge la figura de un dios armado de lanza, con la cual parece herir a una propiciante femenina que alza la visa de la deidad.

In Situ restan otros bellos ejemplares, conocidos desde las publicaciones de Maudslay y Maler. Muchos de estos dinteles contienen la usual ceremonia de los mayas: sacerdotes frente a altares jeroglíficos, pero en otros casos la escena parece tener otra significación; el dintel de la Casa $\mathbf{M}$, por ejenplo, parece representar una escena histórica, ya que un guerrero, ligeramente inclinado y portando bella lanza, parece tomar cautivo a otro guerrero postrado en tierra; similar escena se desenvuelve en el dintel 8 , sólo que aquí son dos los guerreros en el acto de tomar prisioneros a dos esclavos caídos en el suelo, y una de las piezas que podriamos incluir entre las más bellas obras maestras es el dintel $25 \mathrm{del}$ Templo 1lamado por Maler del Tigre (2.15 m. de largo por $1.88 \mathrm{~m}$. de ancho y $0.25 \mathrm{~m}$. de espesor), con una mujer maya vestida con la bella túnica de dibujos reticulados tan usuales en Yaxchilán, en el momento en que entrega en un plato la cabeza de un tigre aderezado para yelmo, está esta escena esculpida en un profundo relieve poco usual en esta ciudad.

Es también en este sitio donde se ha descubierto uno de los pórticos con peldaños esculpidos más bellos del Antiguo Imperio, corroborando lo 
que Maler decia del "altar o terraza" de la estructura 44, tratándose de sucesivas estelas tendidas a manera de escalones o terrazas que dan acceso al Templo (1).

La otra ciudad a que hemos aludido es Piedras Negras, Guatemala, que con poseer pocos dinteles esculpidos, constituyen éstos las más estéticas piezas del arte maya, en especial los dinteles 4 (2) y 3 (3). Ell primero, conocido desde Maler, quien vino a descubrirlo, contiene una escena de carácter histórico, quizá el sojuzgamiento de otra ciudad por el jefe de Piedras Negras, pues está esculpiđa con un alto jefe de magnifico atavio, acompañado de guerrero auxiliar en sus espaldas, mirando a su frente un grupo de cautivos atados que son conducidos por dos guerreros que se arrodillan ante él. Pero la pieza que es la obra maestra en su género, es el dintel 3 recientemente descubierto por Satherwaite, que contiene la fecha 757 de nuestra Era entre los 158 glifos que lo esculpen, cuya escena, recortada en amplio nicho, trabajada en altorrelieve, parece representar una asamblea popular de la tribu: en el trono, en actitud de extender la mano sobre el pueblo, el alto jefe militar; a ambos lados grupos humanos en actitud erguida e inmóviles; y a los pies el pueblo representado por personajes de inferior categoria que escuchan silenciosos al jefe supremo.

(1) Pub. Sylvanus G. Morley: The Inscription of Peten (Catnegie Institution of Washington). Washington, 1939.

(2) Pub. Teoberto Maler: Ob. Cit. Vol. II-1.

(3) Pub. Sylvanas G. Morley: Ob. Cit. 